\title{
Countermeasures of Solid Waste Management in Shale Gas Exploration and Development
}

\author{
Xing-chun $\mathrm{Li}^{1}$, a, Ming Xue ${ }^{1, b}$ and Wen-jia $\mathrm{Xu}^{1, \mathrm{c}}$ \\ ${ }^{1}$ State Key Laboratory of Petroleum Pollution Control, CNPC Research Institute of Safety and \\ Environmental Technology, Beijing, China, 102206

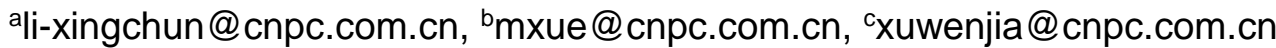

Keywords: Shale Gas, Exploration and Development, Hydraulic fracturing, Hazardous Wastes, Solid Waste.

Abstract: Shale gas development offers a guarantee for energy supply but also brings environmental impacts. The particularity of shale gas development makes the use of oil-based mud indispensable. In this study, following the release of the Environmental Protection Act (2015) and the National Catalogue of Hazardous Wastes (2016), the adjustments and new requirements for the solid waste in the previous edition was compared and the countermeasures of solid waste treatment was proposed. Following the implementation of the new standard and category, the related enterprises need to strengthen solid waste classification and source control. A focus on the technologies regarding harmless disposal and recycling is also required. Furthermore, a joint solid waste treatment plant could further ease the demand for solid waste treatment produced during shale gas development.

\section{Introduction}

Shale gas development in the United States has a history of 80 years. Since 1970s, the US government started to strengthen the shale gas development and its shale gas production in 2012 reached up to $2300 * 10^{8} \mathrm{~m}^{3}$, accounting for $34 \%$ of US natural gas production. The shale gas development has changed the US energy structure, and shale gas has become one of the most important energy sources [1]. In China, shale gas has been found in Paleozoic Cambrian-Silurian, Sichuan Basin Triassic-Jurassic and Ordos's Basin Triassic. In Sichuan Basin, a large scale shale gas reserve with trillion cubic meter has been found, including gas areas as Weiyuan, Changning, Jiaoshi dam, Fushun - Yongchuan, Pengshui and so on [2]. The estimated technically recoverable resources is about $26^{*} 10^{12} \mathrm{~m}^{3}$, almost equivalent to the $24.4^{*} 10^{12} \mathrm{~m}^{3}$ of US. In August 2011, the first batch of shale gas wells in China started trial production. The successful development of shale gas is of great significance to China's energy security. It is expected that the annual output of marine shale gas will reach 200 to $30^{*} 10^{8} \mathrm{~m}^{3}$ in 2020 .

\section{Environmental Impact of Shale Gas Development}

Although the world set off a shale gas boom, European countries vary very much when treating shale gas. Britain and Poland actively support shale gas development [3] while France and Germany choose to limit shale gas development because of environmental considerations. The development process of shale gas, an important unconventional energy, is different from that of conventional oil and gas resources. In shale gas development, drilling, hydraulic fracturing, trial production and production will bring great pressure on the environment.

\section{Well Drilling and Completion Stage}

For the vertical well section of shale gas drilling, clean water, air drilling and water-based drilling fluid is used while for the horizontal well section, oil-based drilling is used (diesel-based or synthetic-based drilling fluid). In this process, a certain amount of waste drilling mud, cutting and drilling waste water is produced. Environmental impact mainly includes: if the drilling waste is leaked of or discharged when not treated as regulations require, there will be a series of negative impacts on the environment like the pollution of surface water, increasing inorganic salt content and 
increasing oil and chemical oxygen demand (COD) concentrations. Land acquisition of the well site, solid waste disposal and pollutant spill will have impact the eco-environment. Nitrogen oxides in the exhaust emissions of engineering vehicles will also pollute atmosphere.

\section{Hydraulic Fracturing Stage}

At present, the fracturing fluid is mainly slick water, main components of which are friction reducer, surfactant, scale inhibitors biocides, clay stabilizer, etc. These compounds will be carried out by the flowback water; hydraulic fracturing generates large noise; the operation also occupies a big area temporarily.

Environmental impact mainly includes: the engineering vehicle exhaust emissions and noise pollution. Diesel engine vents a large amount of high blackness smoke. Compressor of fracturing truck generate noise over $90 \mathrm{db}$ within 10 meters from the truck. The large number of working vehicles and trucks for the transportation of concentrated friction reducer and proppant will affect local traffic condition. During fracturing, there will be many engineering vehicles and a large number of water tanks and temporary pits, which temporarily occupy a relatively large area and have impact on the eco-environment. There is also a potential risk of groundwater pollution in hydraulic fracturing.

\section{Trial Production Stage}

In this stage, almost all the fracturing fluid and some generated water will return to surface in 2 to 4 weeks. Flowback fluid has high temperature, high COD, and high salinity and salt content. Waste water will be reinjected in the re-injection well by tanker after a short sedimentation in the settling pit. The tanker for waste water transportation will cause traffic jam and natural gas venting to the flare will result in waste of resources and serious noise pollution.

Environmental impacts mainly include: waste water will cause environmental pollution if not treated properly; natural gas vented in the flare will bring air and noise pollution; the noise can be as high as $100 \mathrm{db}$ within 50 meters away from the flare; exhaust gas emissions of a large number of transport vehicles will also bring environmental impact.

\section{Production Stage}

When shale gas wells are put in official production, the amount of backflow fluid generated will be low and about $2-3 \mathrm{~m}^{3}$ per day. Taking Congning $201-\mathrm{H} 1$ well as an example, the backflow water per day is only $0.02 \mathrm{~m}^{3}$. Before the operation of auxiliary infusion facilities, there will be some amount of natural gas to be flared.

Environmental impact mainly includes: compared to the previous stages, the impact of production stage on surrounding environment is relatively small. Temporary land should be reclaimed after restoration.

\section{Waste Solid generated in Shale Gas Development}

The biggest difference between the development of shale gas and conventional natural gas lies on the use of horizontal wells and hydraulic fracturing technology. In shale gas drilling, water-based drilling fluid and oil-based drilling fluid system (diesel-based or synthetic-based drilling fluid) is used and a certain amount of waste drilling mud, cuttings will be generated, among which waste oil-based mud and oil-based cuttings are hazardous waste and will have an irreversible impact on the environment if not treated properly.

In the Jiaoshiba region, the current average water-based mud in a single well is $50 \sim 800 \mathrm{~m}^{3}$, and that number for water-based cuttings oil-based cuttings is $1000 \mathrm{~m}^{3}$ and $200 \mathrm{~m}^{3}$. Drilling mud is treated in a recycling manner. When drilling is completed, water-based mud and treated oil-based mud are treated by solidification pit [4]. In the Changning-Weiyuan region, there are about $1200 \mathrm{~m}^{3}$ of water-based cuttings and $400 \mathrm{~m}^{3}$ of oil-based cuttings in a single well. The drilling mud is also recycled. Waste water-based mud and oil-based mud and cuttings will be mainly used for foundation soil and blocks. 


\section{Management Requirements of Hazardous Waste}

\section{Major Requirements}

Ministry of Environmental Protection jointly with the National Development and Reform Commission and the Ministry of Public Security revised and issued National Catalogue of Hazardous Wastes (2016 edition), which came into force on August 1, 2016. Compared with the 2008 edition, the categories of hazardous wastes in 2016 edition were updated. In the 2008 edition, there are 400 hazardous wastes in 49 major categories while in the 2016 edition there are 479 hazardous wastes in 46 major categories [5]. In the 2016 edition, the Hazardous Waste Exemption Management List is added and 16 kinds of hazardous wastes are listed. If exemption conditions are met in those listed exemption links, exemption management can be applied to the hazardous wastes as regulated, which further makes it clear the definition and identification of hazardous wastes. As of shale gas development in the new edition, in the category of waste mineral oil (HW08), mud (071-002-08) generated in treatment of drilling fluid in natural crude oil and natural gas extraction was replaced by waste drilling mud generated in oil exploitation, which is prepared with mineral oil as continuous phase. This means water-based drilling waste is removed from the National Catalogue of Hazardous Wastes. In the newly added Hazardous Waste Exemption Management List, oily wipes and personal protection equipment (900-041-49) are not subject to hazardous waste management. This provision is helpful in reducing these articles in the oil sludge during development and making it easier for subsequent treatment.

In addition, the Technical Specifications for Pollution Control of Used Mineral Oil Recovery, Recycle and Reuse (HJ 607-2011) released by Ministry of Environmental Protection in 2011 requires that during crude oil and natural gas development, oil sludge and oil sand with oil content higher than $5 \%$ shall be recycled; for oil sand, oil content shall be lower than $2 \%$ after oil-sand separation; for oil cuttings, oil content shall be lower than $5 \%$ after oil-cutting separation, and the separated cutting should be burned.

\section{Analysis of Hazardous Wastes Management Trend}

The core of development of the hazardous waste catalogue by the Chinese government is to adhere to problem-orientation in order to achieve fine management of hazardous waste [6], and gradually be in line with hazardous waste catalogue management of major developed countries and regions.

Based on the 2008 edition, the 2016 edition has started to be in line with the international standards. For example, in the 2016 edition, to avoid adverse effect on the management, waste source is still the main basis for hazardous waste classification, which is also consistent with that of the 2008 edition. However, there are some categories that has been merged. There are 479 hazardous waste and 2525 waste hazardous chemicals, which is far more than the number of developed countries and regions. Nonetheless, there are still some obstacles for supervision, such as lack of hazardous waste identification agency, long identification period, high identification cost, unclear base number and disposal status. Even though exemption is available, the coverage is still limited and flexibility is not high enough. The definition of by-products and hazardous wastes is ambiguous and the responsibility of the management level is not clear [7]. Unreasonable layout of disposal facilities, high disposal price and heavy burden of related enterprises are also existed problems [8]. The State will improve the classification management system, establish scientific and standardized identification system and set up identification agencies; the statistical management will be improved [9], hierarchical management procedures will be established[10], and priority and catalogue will be defined; hazardous waste management exemption system will be improved and exemption scope will be expanded; charge of disposal fee will be regulated and construction of disposal facilities will be promoted.

\section{Major Management Measures of Drilling Waste}

\section{Source Control of Drilling Fluid}

Water-based drilling fluid is used for shale gas drilling, while oil-based drilling fluid, synthetic drilling fluid and high inhibition water-based drilling fluid is also used to ensure the wellbore stability, 
lubrication and sticking prevention [11]. In addition to oil-based drilling fluid, environment friendly drilling fluid is also widely used which not only meets the drilling requirement but also reduces environmental pollution. The wellbore geometry is designed to be with conductor (riser), and made up of three sections. 4-layer casings can ensure the isolation with water.

\section{Collecting Waste before Contacting Ground}

On traditional well site, wastes are collected in the waste water pit and cutting pit through ground ditch, which is not suitable for the operation of the multi-well shale gas platform with large pollution. This waste collection method has some shortcomings like water swelling of mutting, field waste accumulation and decentralized pollution, making it more difficult to manage. On the shale gas platform, waste is collected before contact with ground at clean area, which can effectively keep the well site clean and is helpful for in-situ treatment and reuse of cutting.

After scattered waste water and sewage spilled into the collection area and shall be sent to waste water tank or waste collection tank timely with the vacuum suction system. Vacuum suction system should be combined with manual cleaning to clean the circulation tank. The waste can be transferred to cuttings collection tank from upper part of the circulation tank. Vibration shaker and other solid-controlled equipment of cuttings and mud at outlet of vibration shaker and other solid-control equipment will be transported to the cutting tank at front site. All waste collection tanks are equipped with a cover to be rain proof and avoid waste loss. There are also forklifts for internal transportation of the waste on well site.

\section{Real-time treatment and Reuse of Waste}

After transferred to cutting mixing tank in the solidification operation zone, the water-based cuttings are mixed and stirred evenly with added curing agent and stabilizer. Homogenized water-based cuttings will be transferred to solidification landfill pit with good nature of seepage-prevention by excavator. After the solidification pit is filled, the upper part will be sealed by concrete. The concrete is then covered with soil for land recovery and reclamation. According to the requirements of Technical Specification for Harmless Treatment of Drilling Waste (Trial) (Q/SY XN 0276-2015), the moisture content of the solidified body shall not be higher than $65 \%$, and the pollutant concentration in the solidified leachate should reach the Class I level in the Integrated Wastewater Discharge Standard (GB 8978-1996).

The collected oil-based cuttings would be dried and packed in the pretreatment area installed in the platform. Seepage-prevention measures and rain-proof shed are considered for both the pre-treatment and the temporary storage area of cuttings. The transportation and disposal of pretreated bagged cuttings will be handled by enterprises with according qualifications. As relevant emission national standard on oil-based cuttings disposals is still not available, standards like Effluent Limitations for Pollutants from Offshore Petroleum Exploration and Production (GB4914-2008) and Pollution Control Standard for Integrated Utilization of Oily Sludge in Oilfield (DB23/T1413-2010) of Hei longiiang Province and practice in the domestic and abroad could be referred to. CNPC Chuanqing Drilling Engineering Company (CDEC) constructed an oil-based mutting disposal station at both Changning and Weiyuan area. The company carried out thermal desorption and extraction technology experiments with disposal target of oil content less than $1 \%$. After the preliminary verification, the two technologies can meet the requirements.

The remaining drilling fluid will be kept in unified allocation among the platforms and be recycled. Those water-based and oil-based drilling fluid which cannot be recycled will be disposed together with water-based cuttings and oil-based cuttings.

\section{Main Existing Problems}

In the 2016 edition, the newly added exemption list only clarifies partial exemption management of hazardous waste management in the event of an accident, and fails to clearly define management of disposal of crude oil-contaminated soil, oil sludge and oil cutting generated during oil and gas development. These are the urgent problems needed to be solved in shale gas exploration and development. 


\section{Countermeasures of Solid Waste Management}

In the previous edition, the water-based mud is not clearly defined. In the 2016 edition of National Catalogue of Hazardous Waste, water-based mud is removed, which is beneficial to the overall waste management. However, the newly added exemption list only clarifies partial exemption management of hazardous waste management in the event of an accident, and fails to clearly define the management of disposal of crude oil-contaminated soil, oil sludge and oil cutting generated during oil and gas development. These are urgent issues needed to be addressed in shale gas exploration and development. Moreover, under the new national catalogue of hazardous waste, previous management principles of solid waste should be adjusted in the shale gas development.

Firstly, classification and statistical analysis of solid waste shall be strengthened. The existing classification management has been unable to meet the management requirements of the new catalogue, and the statistical analysis system should be improved in accordance with the requirements of the new catalogue.

Secondly, the new catalogue clearly defines that all waste listed are hazardous waste and should be managed as hazardous waste except for those exemptions. There is no possibility of applying for identification in the 2008 edition. For those wastes with objections, more basic research should be strengthened and the amendment suggestion could be proposed when the Environmental Protection Agency of China revises it. For the categories not listed, the state has clarified that not all waste are general solid waste, and for those waste with different opinions the administrations could request for identification and then applied to manage as hazardous waste. The relative enterprises should also strengthen basic research and identification of specific solid wastes to provide basis for the country-wide management of hazardous waste, which is also good for the management of solid waste. Thirdly, there are few hazardous waste disposal sites in the area where shale gas development is concentrated and the cost is high. In this case, the relevant enterprises should enhance the scientific planning. When possible, enterprises in the same region could jointly establish a hazardous waste treatment plant to meet the internal disposal requirements.

Fourthly, based on the removals, exemptions and amendments in the new national catalogue, enterprises should classify and segregate solid waste when disposing it. Currently, the core work of hazardous waste disposal is waste minimization. Next is waste recycling and harmless treatment. Priorities should be given to related technologies according to this target.

Fifthly, there are clear requirements on some amendments and exemption provisions. For instance, exemptions of 900-042-49 shall meet the requirements that the exemption should be agreed by the environmental protection authorities on city or county level and the waste should be transferred, disposed or reused in accordance with emergency disposal plan proposed by these authorities. Related enterprises should carry out research and propaganda work on these provisions to make sure that they are executed properly.

\section{Conclusions}

Following the implementation of the 2016 edition of National Catalogue of Hazardous Wastes, the solid waste produced from shale gas exploration and development are facing a new challenge. The related enterprises in shale production area should build a scientific plan after classification and statistical analysis of the solid waste, and prioritize the utilization of technologies regarding recycling and harmless treatment of those solid waste. Nevertheless, a joint hazardous treatment plant should also be constructed by the related enterprises when solid waste disposal is constrained.

\section{Acknowledgements}

This work was financially supported by the National Science and Technology Major Project "Large Oil and Gas Fields and Coalbed Methane development" (No. 2016ZX05040003). 


\section{References}

[1] X.D. Zhang, T.Y. Yang: Acta Petrolei Sinica. Vol. 34 (4) (2013), p. $792-801$ (In Chinese).

[2] C.N. Zhou, D.Z. Dong, Y.M. Wang: Oil Explor. and Development. Vol. 42(6) (2015), p. 689-701 (In Chinese).

[3] M. Peng, H.B. Yang, Y.X. Li: Resource Development \& Market. Vol. 31(3) (2015), p. 327-33 (In Chinese).

[4] D.M. Xiong, S.L. Zhang, B. Feng: Journal of Xi'an Shiyou University (Natural Science Edition). Vol. 31(6) (2016), p. 48-53 (In Chinese).

[5] Interpretation of National Catalogue of Hazardous Wastes (2016 Edition): China Resources Comprehensive Utilization. Vol. 34(6) (2016), p. 15-16 (In Chinese).

[6] H.L. Hu, Y. Zheng, R. Guo: Chinese Journal of Environmental Management. Vol. 8(4) (2016), p. 76-81 (In Chinese).

[7] G.M. Qiao, W.L.Wang: Environment and Sustainable. Vol. 39(3) (2014), p. 105-106 (In Chinese).

[8] C.J. Chu, Y. Wang, H.K. Zang: Environment Protection. Vol. 44(19) (2016), p. 59-61 (In Chinese).

[9] P. Zha: Environment Economics. Vol. 175-176(07-08) (2016), p. 91-95 (In Chinese).

[10] Y.L. Hao, H.L. Hu: China Environmental Protection Industry. Vol. 3 (2016), p. 21-23 (In Chinese).

[11] C.L. Qi: Chemical Industry Times. Vol. 28(10) (2014), p. 40-46 (In Chinese). 